\title{
Shaping Ability, Cyclic Fatigue Resistance and Fractographic Analysis of Hybrid and Reciprocating Nickel Titanium Endodontic Instruments
}

\author{
Saulius Drukteinis* $*$, Vytaute Peciuliene, Ruta Bendinskaite $₫$, Vilma Brukiene, \\ Rasmute Maneliene $\mathbb{D}$ and Egle Nedzinskiene \\ Institute of Dentistry Faculty of Medicine Vilnius University; Zalgirio 115, LT- 08217 Vilnius, Lithuania; \\ vytaute.peciuliene@gmail.com (V.P.); rutabend@gmail.com (R.B.); vilma.brukiene@mf.vu.lt (V.B.); \\ rasmutemaneliene@gmail.com (R.M.); nedzinskieneegle@gmail.com (E.N.) \\ * Correspondence: saulius.drukteinis@gmail.com; Tel.: +37-06-104-1808
}

Received: 3 January 2020; Accepted: 23 January 2020; Published: 24 January 2020

\begin{abstract}
The aim of this study was to investigate the shaping ability and cyclic fatigue resistance of Genius (GN) and WaveOne (WO) nickel-titanium (NiTi) instruments. Forty mesial root canals of mandibular molars were randomly divided into two groups, according to the instrument system used for root canal preparation $(n=20)$ : GN and WO. Root canals were prepared to the full working length using the crown-down technique, with up to 40.04 instruments for GN group and 40.08 instruments for WO group. Specimens were scanned with a $\mu \mathrm{CT}$ before and after instrumentation. The changes in 3D parameters and degree of canal transportation were evaluated in the apical, middle and coronal thirds of root canals. Size 25, taper $0.04(\mathrm{GN})$ and 0.08 (WO) instruments $(n=20)$ were used in simulated root canals until fracturing, and the number of cycles to failure (NCF) was recorded. The fractured files were investigated under a scanning electron microscope to characterize fractured surfaces. Data were analyzed using ANOVA post hoc Tuckey's tests with the significance level set at 5\%. The GN system was able to prepare the higher percentage of the canal surface with less canal transportation in all root canal thirds and displayed the higher resistance to cyclic fatigue in comparison to WO instruments $(p<0.05)$. However, the length of the fractured segments was not significantly different among the groups; meanwhile, SEM investigations revealed the typical topographic characteristics of fractured surfaces. Hybrid GN instruments demonstrated superior shaping ability and resistance to cyclic fatigue. However, both NiTi instrument systems prepared the root canals with no significant shaping errors, considerable changes in 3D parameters and no significant differences in the topographic appearances of the instrument surfaces after fractures.
\end{abstract}

Keywords: cyclic fatigue; hybrid movement; micro-computed tomography; reciprocating movement; root canal shaping; transportation

\section{Introduction}

The quality of root canal cleaning and shaping directly impacts the outcome of endodontic treatment and is one of the most challenging tasks in endodontics [1,2]. Numerous studies have shown that procedural mishaps, such as canal transportations, perforations, blockages or ledges, can occur during endodontic treatment, leading to complicated canal obturation, an unsatisfactory apical seal or worse clinical outcomes [1,3-5]. The previous studies have shown that the alloy, design and kinematics of the instrument are essential features of the files affecting the efficiency and the shaping ability of the instruments, and resistance to torsional stresses and fractures $[4,6]$.

The introduction of the nickel-titanium (NiTi) instruments for root canal shaping in 1988 was a substantial innovation in endodontics and clinically appealing in terms of minimizing the number of 
procedural errors occurring during root canal instrumentation [3,4]. NiTi instruments exhibit a superior elasticity and enable clinicians to prepare root canals to desirable shape and taper, without considerable shaping mishaps [4]. However, despite the many advantages, NiTi instruments are not entirely resistant to deformation and fractures. Moreover, fractures of NiTi instruments usually occur suddenly without any visible sign of deformation, and it is a significant clinical problem. It has been shown that instrument fractures are related to cyclic fatigue and torsional failure during canal preparation. The most crucial factor that leads to instrument separation is metal fatigue, which is especially predominant when working in moderately curved root canals [1]. Instrument fractures are induced by repeated cycles of tension-compression during the movement of the instrument. Contrastingly, at the flexural point in the root canal curvature, the endodontic instruments are experiencing constant and alternate tension-compression deformations, leading to the formation of the microcracks and its propagation to the instrument separation subsequently [4]. Furthermore, previous studies have shown that during manufacturing some scratches and small defects are left on the instrument surfaces, what can lead to increased risk of the instrument separation during endodontic treatment.

To increase the resistance of the engine-driven endodontic instruments to torsional stresses and cyclic fatigue, the use of the reciprocation movement was suggested [4]. The previous studies have shown that changes in instrument kinematics increase the cyclic fatigue resistance of the instruments significantly; reciprocating NiTi instruments are more resistant to cyclic fatigue in comparison to rotary NiTi files [4]. However, the reciprocation movement is associated with an increased probability to extrude debris periapically during root canal shaping $[5,6]$.

The Genius instrument system was recently developed as a hybrid asymmetric reciprocation-rotary system (GN; Ultradent Products Inc., South Jordan, UT, USA) containing six endodontic instruments: the Orifice shaper and five shaping files. The main design features of the GN instruments are austenite NiTi alloy, S cross-sections, modified flutes and a non-cutting tip [7]. The manufacturer claims that GN instruments can be used in asymmetric reciprocating as well as continuous rotating movements [8]. The files are used in a safer asymmetric reciprocation movement to reach full working length, and at the final step of shaping procedure, files are driven in a rotary mode to maximize the removal of accumulated debris from the root canal [8].

WaveOne (WO; Dentsply Sirona, Ballaigues, Switzerland) instruments were introduced as a single-file preparation technique [9]. The single-use of the instrument; reciprocating movement; concave, triangular cross-section; increased flexibility; and resistance to fractures due to the modified M-wire NiTi alloy, are the main characteristics of WO files $[10,11]$. Previous studies have shown that shaping capability of WO instruments is comparable to multifile rotary systems [12]. However, single-file systems are more beneficial for clinicians because they are easier to apply, are cheaper and are more time consuming than full sequence NiTi rotary file systems [9].

It has been shown that the micro-computed tomography $(\mu \mathrm{CT})$ is a modern, repeatable and reliable method to assess the three-dimensional (3D) parameters of the root canals before and after preparation $[13,14]$. There are a few published scientific articles about the shaping ability and cyclic fatigue resistance of WO instruments $[9,15,16]$. However, just one recently published study compared the GN instruments and rotary files, regarding the 3D changes in the root canals after instrumentation [7]. However, there is no data published about the effectiveness and performance of the hybrid GN instruments in comparison to reciprocating file systems. Therefore, the scope of this study was to evaluate and compare the shaping ability of GN and WO instruments in curved canals of mandibular molars using $\mu \mathrm{CT}$ and the cyclic fatigue resistance of the instruments. 


\section{Materials and Methods}

\subsection{Shaping Ability Evaluation}

\subsubsection{Sample Preparation}

The approval of the local ethical committee was received for this study (protocol number EK-2). In total, 20 extracted human mandibular molars with a moderate $10-20^{\circ}$ curvature of the mesial roots, according to Schneider's method [17], were selected for this study. The standard endodontic access cavities were prepared and the presence of two separate root canals in the mesial root were identified, inserting a size 10 K-file (Dentsply Sirona, Ballaigues, Switzerland) to the full working length (WL). The teeth crowns were removed at the cement-enamel junction using EndoAccess (Dentsply Sirona) burs.

To establish the $\mathrm{WL}$, a size $10 \mathrm{~K}$-file was inserted into the root canal until the tip of the instrument was visible at the apical foramina; the instrument was subsequently retracted $1 \mathrm{~mm}$, and WL was determined. Subsequently, size $15 \mathrm{~K}$-Flexofile and $20 \mathrm{~K}$-Flexifile instruments up to WL were inserted into the canal to create a glide path. Teeth were randomly divided into two groups $(n=20)$ according to the instrument system used for canal instrumentation: GN and WO. Root canals were shaped using the crown-down technique according to the manufacturer's instructions.

GN instruments were driven in a $90^{\circ}$ clockwise $/ 30^{\circ}$ counterclockwise hybrid rotary-asymmetric reciprocation movement following the manufacturer's recommendations. Instruments were used with the Genius ${ }^{\circledR}$ motor (Ultradent Products Inc., South Jordan, UT, USA) at the constant speed of $350 \mathrm{rpm}$. To shape the coronal and middle thirds of the root canals, the OS 30.08 file was used in a rotary movement. Subsequently, shaping files 25.04, 35.04 and 40.04 were used in asymmetric reciprocation movement until the WL was reached; and at the terminal step of shaping procedure, the endodontic motor was switched to rotary mode.

In the WO group, WaveOne Primary (25/0.08) instrument was slowly inserted into the canal, activated in reciprocating movement and moved apically with light pressure using an in-and-out pecking motion. Instruments were inspected and cleaned off after three pecking motions. The procedure was repeated until the file reached the full WL without any binding and resistance. WaveOne Large (40/0.08) file was used in the same manner to the WL. Instruments were driven at the speed of $350 \mathrm{rpm}$ with the WaveOne motor (Dentsply Sirona, Ballaigues, Switzerland) using preset parameters "WaveOne All".

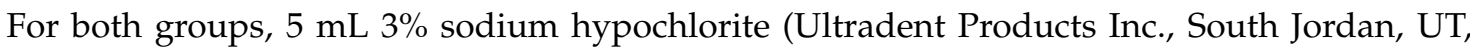

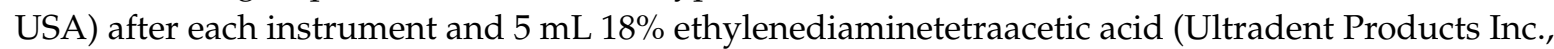
South Jordan, UT, USA) for 2 min as a final flush were used. Irrigants were delivered using disposable syringes and 31-G NaviTip needles (Ultradent Products Inc., South Jordan, UT, USA). Root canals were dried with paper points and the specimens were repositioned to the specimen holder for postoperative scanning. The same operator-a trained endodontist, performed all procedures.

\subsection{2. $\mu \mathrm{CT}$ Scanning and Data Analysis}

The samples were scanned before and after root canal preparation with a $\mu$ CT scanner SkyScan 1173 (Bruker-microCT, Kontich, Belgium) at $10 \mathrm{kV}, 50 \mathrm{~mA}$ and an isotropic resolution of $22.8 \mu \mathrm{m}$, using a $1 \mathrm{~mm}$ aluminium filter, $180^{\circ}$ rotation and a rotation step of 0.18. NRecon v.1.6.9 (Bruker-microCT, Kontich, Belgium) software was used for images reconstruction with a ring artefact reduction factor of 5 and beam hardening correction of $30 \%$.

The volume of interest (VOI) for all assessments was selected from cementoenamel junction to the apex of each mesial root. The cross-sectional images before and after root canal shaping were coregistered using the DataViewer version 1.5.1 software (Bruker microCT, Kontich, Belgium). 2D and $3 \mathrm{D}$ volumetric analysis, and measurements of the volume of the root canals, the amount of removed dentin and surface area were performed using CTAn version 1.14.4 software (Bruker microCT, Kontich, 
Belgium). Finally, the CTVol 1.10.1.0 software (Bruker microCT, Kontich, Belgium) was used for 3D volumetric visualization.

The magnitude of the root canal transportation was evaluated using the DataViewer version 1.5.1 software (Bruker microCT, Kontich, Belgium) on a comparison of the coregistered cross-sectional images at 3, 6 and $9 \mathrm{~mm}$ from the apex as described by Gambill et al. [18]. The degree of canal transportation was determined in millimeters using the formula: [X1 - X2] - [Y1 - Y2]. X1 represents the shortest distance from the mesial edge of the unprepared root canal to the mesial edge of the root, and $\mathrm{Y} 1$ is the shortest distance from the distal edge of the unprepared root canal to the distal edge of the root. $\mathrm{X} 2$ represents the shortest distance from the mesial edge of the unprepared root canal to the mesial edge of the root, and Y2 is the shortest distance from the distal edge of the unprepared canal to the distal edge of the root (Figure 1). According to the formula, a "0" value means no canal transportation, a positive value represents transportation distally and a negative value represents transportation medially.

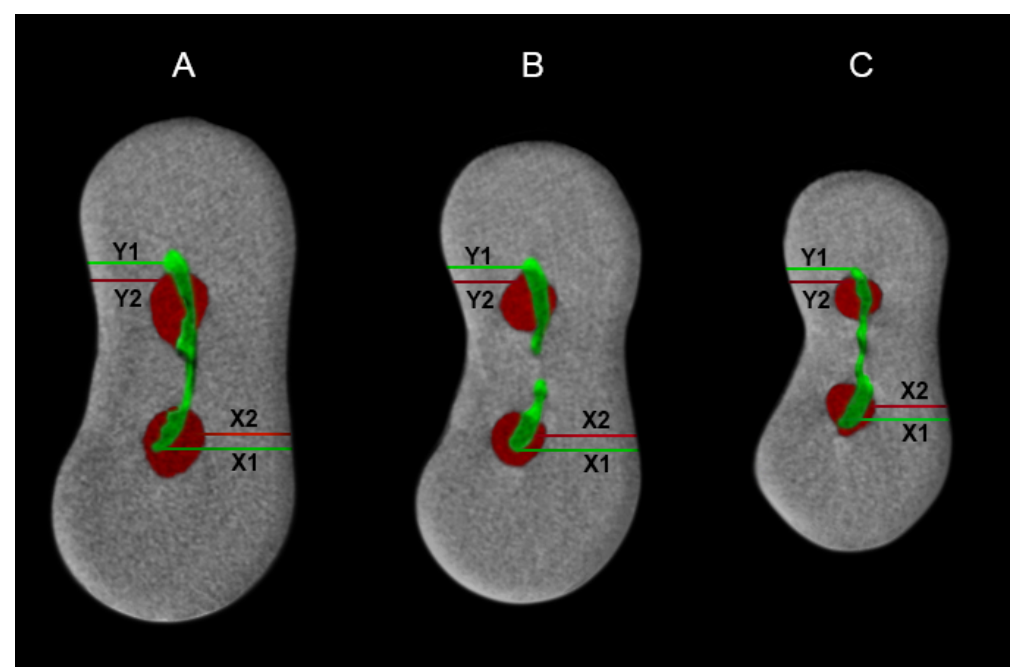

Figure 1. Cross-sectional images representing reference points of measurements before (green) and after (red) root canal preparation at 9 (A), 6 (B) and $3 \mathrm{~mm}(\mathbf{C})$ from the apex.

\subsection{Cyclic Fatigue Resistance Test}

A total of 20 Genius (\#25/taper 0.04/length $25 \mathrm{~mm}$ ) and 20 WaveOne instruments (number 25/taper $0.08 /$ length $25 \mathrm{~mm}$ ) were used for a cyclic fatigue testing. The stainless steel cyclic fatigue testing device was made for the experiment. The simulated root canal was obtained by combining two adjustable metal frames-blocks containing two halves of the root canals. After screwing two frames-blocks into the uniform device, a simulated root canal was created (Figure 2). The artificial canal had a $60^{\circ}$ angle and $5.0 \mathrm{~mm}$ radius of curvature, while the center of the curvature was $5.0 \mathrm{~mm}$ from the tip of the testing instrument. Before the cyclic fatigue test, an artificial canal was filled with glycerin to reduce the friction of the instrument.

The GN and WO instruments were inserted into an artificial canal filled with glycerin to decrease the grinding of the instrument to the metallic surface of the simulated canal. Instruments were driven in reciprocating movement until instruments' failure and fractures. The GN files were used at the speed of $350 \mathrm{rpm}$ with the Genius ${ }^{\circledR}$ motor (Ultradent Products Inc., South Jordan, UT, USA). WO files were driven at the speed of $350 \mathrm{rpm}$ with the WaveOne motor (Dentsply Sirona, Ballaigues, Switzerland) and with the "WaveOne All" settings.

The time to instrument failure and fracture was recorded visually in seconds using the digital desktop stopwatch. The number of cycles to failure (NCF) was determined by multiplying the time to failure by the number of cycles per second ( 6.33 rotation cycles per second/350 rpm). The length of the fractured file fragments was measured by using a digital micro caliper (Mitutoyo, Kawasaki, Japan). 

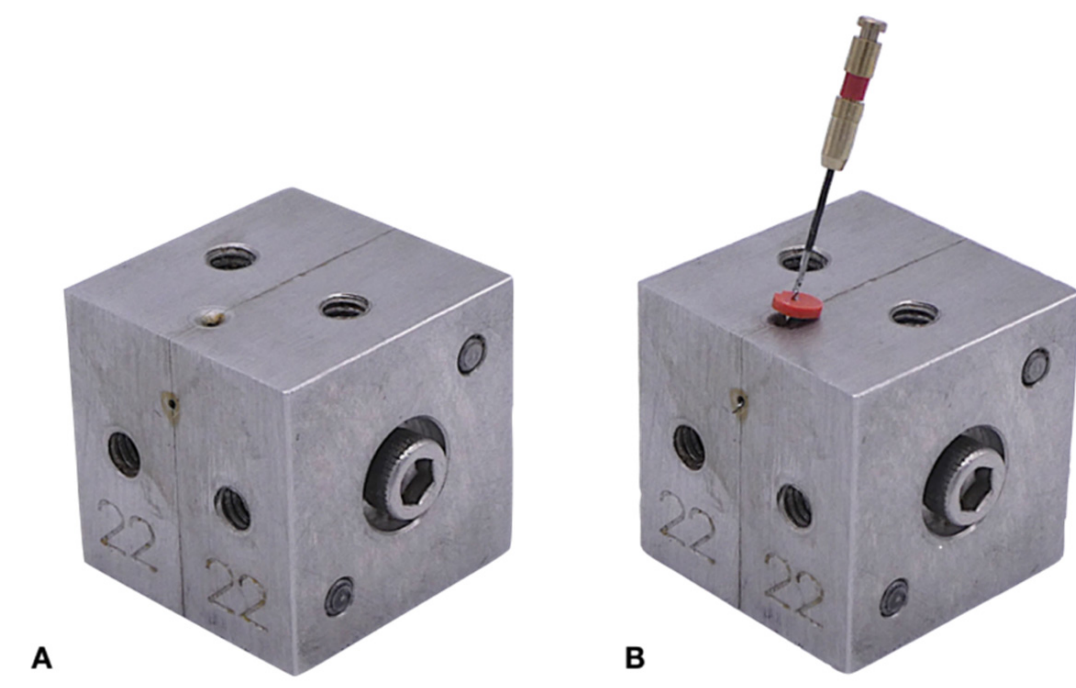

Figure 2. The custom-fabricated stainless steel cyclic fatigue testing device (A) with the tested endodontic instrument inserted into a simulated root canal (B).

\subsection{Fractographic Analysis}

Two new unused NiTi files and three fractured files after the cyclic fatigue test in each group were mounted on aluminum holders with adhesive carbon tape and examined using a scanning electron microscope (T3030; Hitachi Ltd., Tokyo, Japan). The SEM of the surface, tip and fractured section structures was done in a near vacuum using a secondary electron image mode, with the instrument operating at $15 \mathrm{kV}, \times 50$ and $\times 200$ magnification.

\subsection{Statistical Analysis}

The normality of the data was confirmed by Shapiro-Wilk test. The differences between the groups were compared using one-way analysis of variance (ANOVA) followed by Tukey's post hoc test. The significance level was set at 5\%. SPSS 25.0 software (SPSS Inc, Chicago, IL, USA) was used for data analysis.

\section{Results}

\subsection{Shaping Ability Evaluation}

The volumetric analysis revealed no differences regarding the preoperative volumes of the untreated root canals between the experimental groups $(p>0.05)$. These findings indicated that experimental groups were equal in terms of initial parameters tested. Nevertheless, the comparison of the postoperative changes in 3D parameters between the groups showed significant differences (Table 1). The mean volume of removed dentin, and the percentage of unprepared root canal surface, were significantly lower in the GN group in comparison with WO $(p<0.05)$.

Table 1. Mean values and standard deviations (SD) of the differences in 3D parameters between experimental groups.

\begin{tabular}{clccc}
\hline Group & $\boldsymbol{n}$ & $\begin{array}{c}\text { Volume of Untreated } \\
\text { Canal }\left(\mathbf{m m}^{\mathbf{3}}\right)\end{array}$ & $\begin{array}{c}\text { Volume of Removed } \\
\text { Dentin }\left(\mathbf{m m}^{\mathbf{3}}\right)\end{array}$ & $\begin{array}{c}\text { Percentage of Unprepared } \\
\text { Canal Surface }\end{array}$ \\
\hline GN & 20 & $3.54 \pm 1.26$ & $2.14 \pm 0.59^{\mathrm{a}}$ & $41.66 \pm 5.69^{\mathrm{a}}$ \\
WO & 20 & $3.48 \pm 1.12$ & $2.61 \pm 0.71^{\mathrm{b}}$ & $45.52 \pm 5.11^{\mathrm{b}}$ \\
\hline \multicolumn{4}{c}{}
\end{tabular}

Different superscript letters indicate significant differences between groups $(p<0.05)$. 
The magnitude of root canal transportation at coronal, middle and apical thirds of the root canals was significantly lower with GN instruments in comparison to WO files $(p<0.05)$ (Table 2).

Table 2. The magnitude of transportation of mesial root canals after shaping with tested instruments $(\mathrm{mm} \pm \mathrm{SD})$.

\begin{tabular}{ccccc}
\hline Group & $\boldsymbol{n}$ & Coronal Third & Middle Third & Apical Third \\
\hline GN & 20 & $0.03 \pm 0.02^{\mathrm{a}}$ & $0.02 \pm 0.01^{\mathrm{a}}$ & $-0.01 \pm 0.04^{\mathrm{a}}$ \\
WO & 20 & $0.05 \pm 0.03^{\mathrm{b}}$ & $0.04 \pm 0.02^{\mathrm{b}}$ & $-0.04 \pm 0.05^{\mathrm{b}}$ \\
\hline
\end{tabular}

A negative value indicates transportation medially. A positive value indicates transportation distally. Different superscript letters indicate significant differences between groups $(p<0.05)$.

However, both instrument systems prepared root canals with no substantial shaping errors and considerable changes in 3D parameters. The representative 3D reconstructions of the specimens are shown in Figure 3.

A
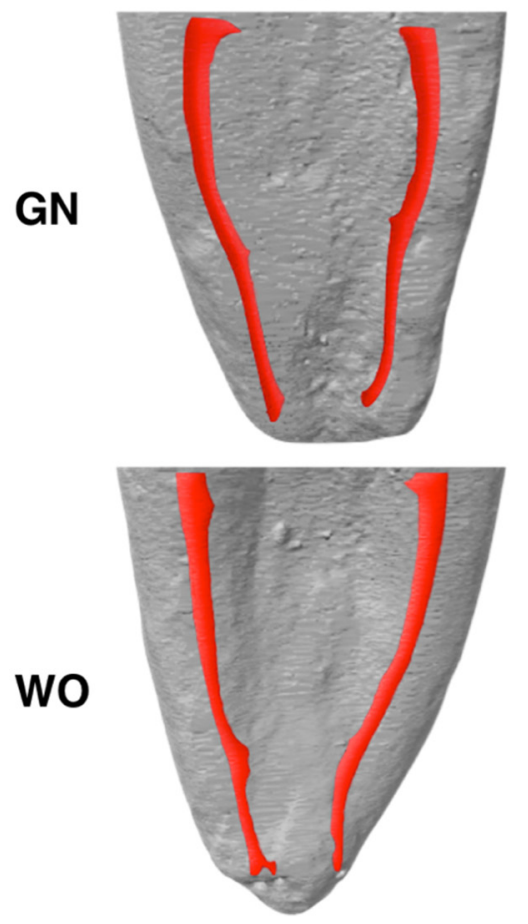

B
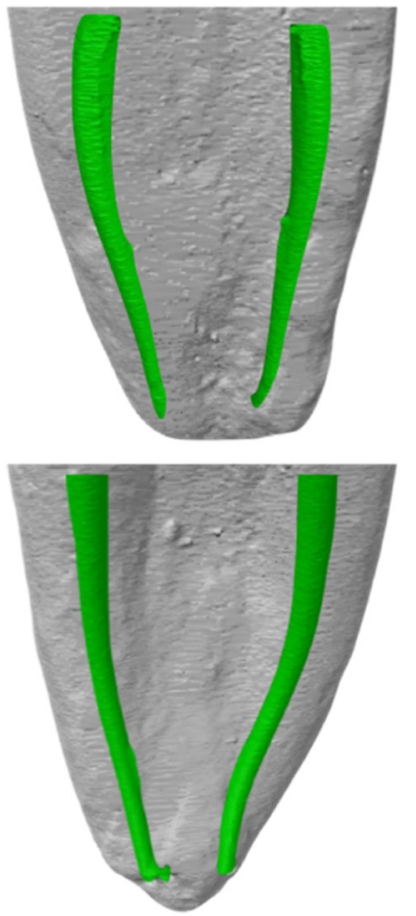

C
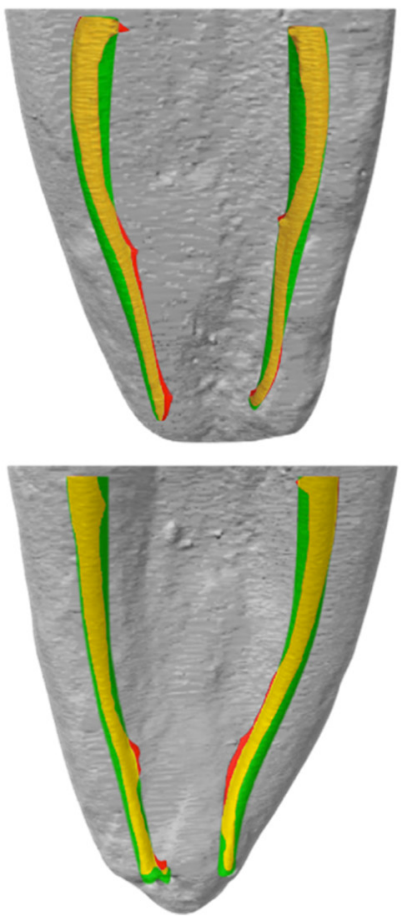

Figure 3. 3D reconstructions of the mesial root canals for Genius (GN) and WaveOne (WO) groups: preoperative reconstructions (A); postoperative reconstructions (B); superimposed reconstructions (red indicates unprepared canal surface) (C).

\subsection{Cyclic Fatigue Resistance Test}

Table 3 presents the data for the number of cycles to fracture (NCF). The Genius files exhibited a statistically higher number of cycles until fracture in comparison to WO instruments $(p<0.05)$. The lengths of the fractured fragments were recorded to assess the accurate positioning of the specimens inside the artificial canal. No statistically significant differences in the length of the separated fragments were detected $(p>0.05)$. 
Table 3. Means \pm standard deviations of the numbers of cycles to fracture (NCF) and lengths of fractured fragments between instrument systems tested.

\begin{tabular}{cccc}
\hline Measurements & $\boldsymbol{n}$ & Genius & WaveOne \\
\hline NCF & 20 & $2141.53 \pm 473.38^{\mathrm{a}}$ & $1583.02 \pm 444.35^{\mathrm{b}}$ \\
Length of the fragment $(\mathrm{mm})$ & 20 & $4.35 \pm 0.43$ & $4.12 \pm 0.82$ \\
\hline
\end{tabular}

Different superscript letters indicate significant differences between groups $(p<0.05)$.

\subsection{Fractographic Analysis}

The surface investigation by scanning electron microscope of the new and unused GN and WO files revealed some differences between the two instruments (Figure 4). As both instruments were produced by grinding, many mechanical grooves were visible on the file surfaces. However, the surfaces of GN instruments were considerably smoother in comparison to those of WO. Milling marks and scratches on WO instruments were deeper, wider and more regular. Furthermore, the dust-like structures were observed on the surfaces of both instruments.
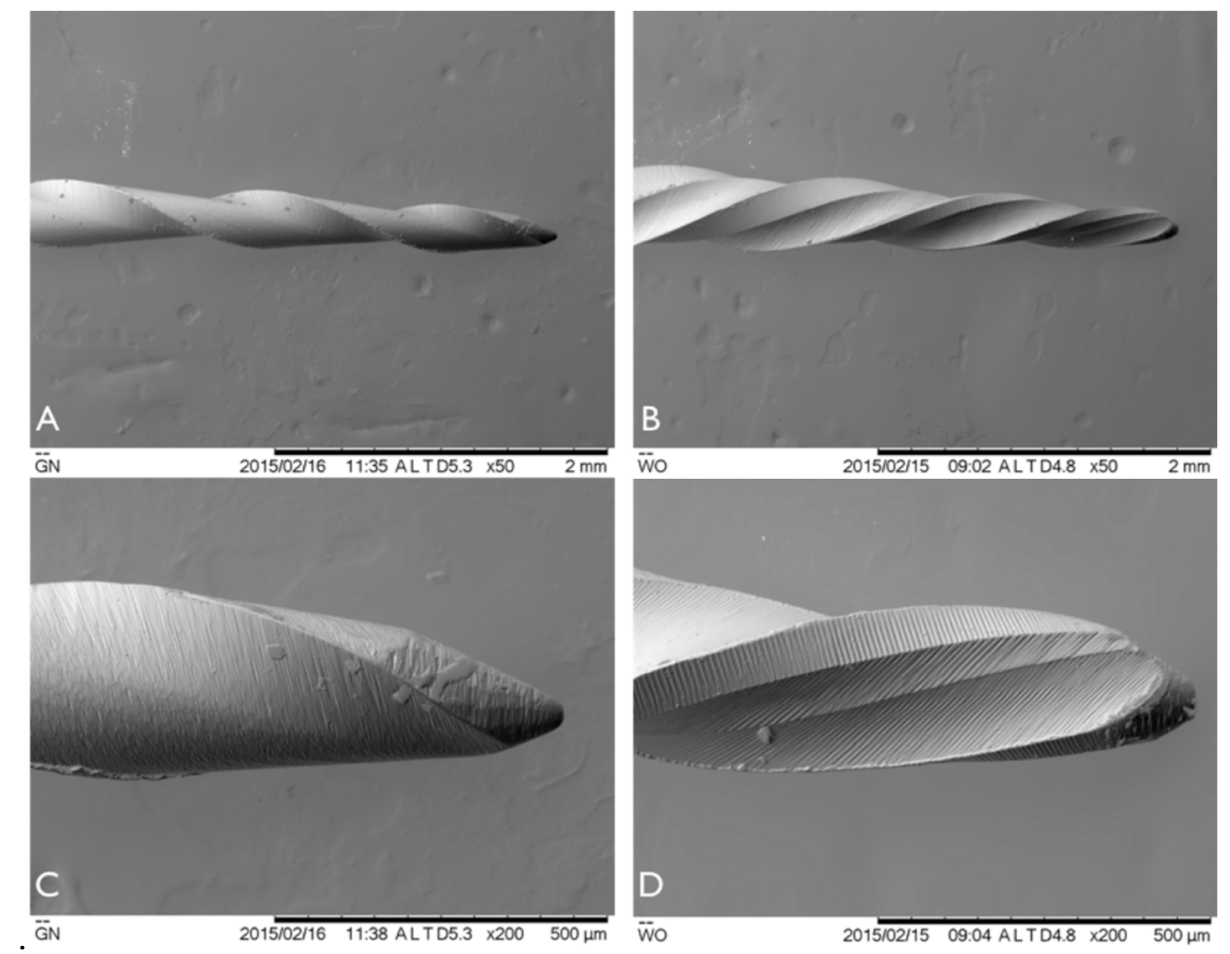

Figure 4. Micrographs of new GN instruments $(\mathbf{A}, \mathbf{C})$ and $W O$ instruments $(\mathbf{B}, \mathbf{D})$ at $\times 50$ and $\times 200$ magnification. The differences in files surface structure are noticeable at both magnifications.

Fractographic analysis of the instruments after cyclic fatigue test revealed multiple cracks along mechanical grooves on both NiTi files (Figure 5). All cracks on the instrument surfaces were the continuation of fatigue cracks originated at the cutting edges of the files. The cross-sections of fractured surfaces demonstrated typical topographic views of the files after cyclic fatigue testing: crack origin zones; microscopic dimples on the fracture surfaces; and fatigue and overload fast fracture zones. 

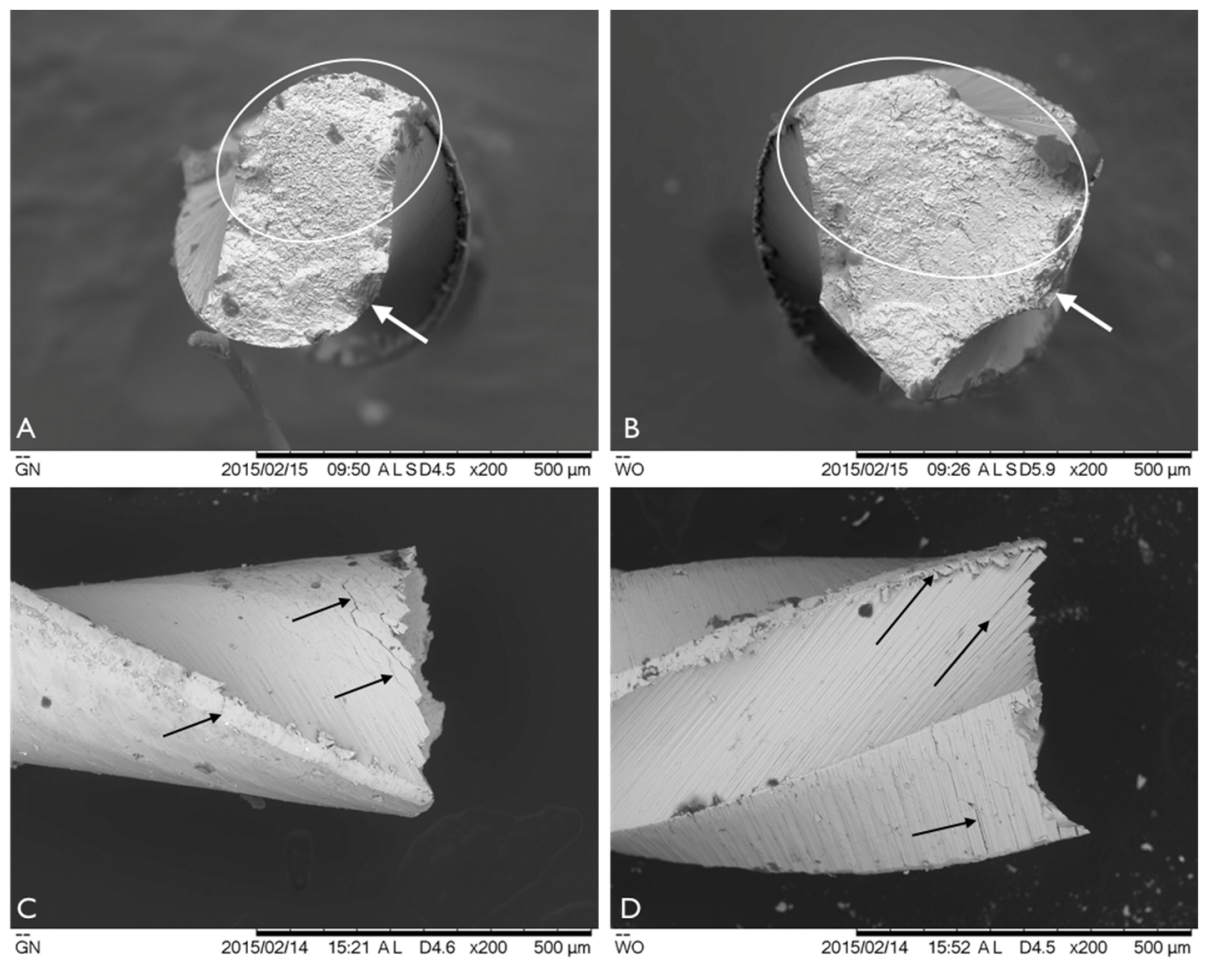

Figure 5. SEM micrographs of the fractured cross-sectional and side surfaces of separated fragments of GN (A,C) and WO (B,D) files after cyclic fatigue test. Microbubbles, craters, irregularities and dimples represent typical topographic characteristics of the fracture surface $(\mathbf{A}, \mathbf{B})$. Crack initiation (white arrows) and overload fast fracture zones (white oval) on the surfaces. Side view of the alterations in instruments after testing (black arrows): blunt or disrupted edges, cracks along mechanical grooves on the instrument surface.

\section{Discussion}

The modern endodontic instruments, due to the new alloys, innovative design and kinematics, are more flexible, more resistant to fractures and more efficient in the shaping of the root canals [4]. The extensive testing of the newly developed instruments has crucial clinical importance, as it helps to assess the main behavioral parameters, such as efficiency, performance and resistance to fracture, of each instrument under different conditions. It has been shown that rotary and reciprocating endodontic instruments can be equally efficient in root canal cleaning and shaping, and even have similar cyclic fatigue resistance $[12,19]$. The preservation of the original root canal configuration and lack of procedural errors, such as root canal transportation, and avoidance of instrument separation, is directly related to the higher success rates of endodontic treatment and survival of the endodontically treated teeth [20]. During the last decade, the $\mu \mathrm{CT}$ imaging has been the most widely used method to precisely quantify and qualify many 3D parameters of the root canals after cleaning and shaping procedures $[7,12,21]$. It has been shown that extracting natural teeth is superior to simulating root canals for testing the shaping abilities of endodontic instruments, as they represent more realistic clinical conditions [22,23]. Consequently, the mandibular molars were selected for comparative assessment of the instruments.

This study comparatively evaluated only a few clinically important features, such as the shaping ability of hybrid (GN) and reciprocating (WO) NiTi systems in the curved mesial root canals of mandibular molars using $\mu \mathrm{CT}$. The instrument systems varied regarding the NiTi alloy, cross-sectional design, number of movements and type of movement of the instruments. The comparison between groups displayed significant differences regarding changes in 3D parameters after preparation, and the hybrid GN system demonstrated a superior shaping ability compared to the reciprocating WO system. Previous findings revealed that the shaping ability of the hybrid GN instruments is not superior 
to rotary endodontic instruments [7]. However, no studies have compared the efficiency of these instruments to reciprocating systems. Instrumentation with GN and WO left $41.66 \%$ and $45.52 \%$ of the canal walls uninstrumented, respectively. The previous studies demonstrated that the percentage of unprepared root canal wall surfaces could reach $47.6 \%$ and directly depend on the root canal geometry before preparation, the alloy and design features of the files and the preparation technique used for instrumentation $[5,6,24]$.

Paque F et al. [25] found that there is a direct correlation between the percentage of prepared root canal wall surfaces and the taper of the instruments' files, with a bigger taper preparing larger surfaces of entire root canals. However, De-Deus G et al. found [16] that the ability of the instrument to prepare larger surfaces of canal walls does not directly correlate with the taper size of the instrument. The results of the present study are in agreement with these findings: WO system has larger tapers (0.08) in comparison to the GN system (0.04) but demonstrates the higher percentage of uninstrumented canal surface.

It has been shown that reciprocating file systems resulted in a less centered, more invasive preparation and produced more root canal transportation in comparison to the conventional or thermal treatment NiTi alloy rotary files [15,21]. The previous report indicated that hybrid Genius instruments are comparable to BioRace and ProTaper NEXT rotary file systems regarding the degree of the root canal transportation [7]. However, no published data compares the impacts of root canal preparation with hybrid and reciprocating endodontic instruments; therefore, it was impossible to compare our results with previous findings. The present study disclosed that the magnitude of root canal transportation was less in the GN group in comparison to WO instruments, and newly developed hybrid movement GN instruments had a negligible effect on root canal transportation. It has been shown that transportation of the apical third of the root canal surpassing $0.3 \mathrm{~mm}$ may have an undesirable impact on the quality of the canal obturation [26]. However, the magnitude of transportation in our study did not exceed the critical limit for both instrument systems evaluated. Although the transportation magnitude for WO instruments was higher in comparison to GN files, the clinical relevance of the transportation of the moderately curved canals by hybrid and reciprocating instrument systems remains questionable [15].

It has been concluded that extrusion of the debris periapically directly depends on the movement of the instruments: rotary instruments remove more debris from the root canals and extrude less debris through the apex in comparison to reciprocating files [16,27]. However, the rotary endodontic instruments are less resistant to torsional stresses and fractures during root canal instrumentation $[4,14]$. The newly developed GN instruments combine both asymmetric reciprocation and rotary movements of the same instrument during different phases of root canal debridement. Hybrid movement of the Genius instruments hypothetically can be clinically advantageous because it allows combining the safety of reciprocating and the effectiveness of rotary movements during root canal preparation. However, more research is needed to confirm the superior clinical efficacy of hybrid endodontic instruments.

It has been concluded that cyclic fatigue resistance of the NiTi endodontic instruments highly depends on the alloy, cross-sectional design and the manufacturing method [28,29]. The extensive testing of the cyclic fatigue of newly developed instruments has a significant clinical importance [4]. The resistance of an endodontic instrument to cyclic fatigue, regardless of the alloy used in the instrument's manufacturing, highly depends on the angle and radius of canal curvature and the size and taper of the instrument [1]. Instruments in the root canals with moderate angles and increased radii of curvature undergo higher torsional stresses in comparison to straight root canals [28]. Clinically, cyclic and torsional fatigue is associated with the anatomy of the root canals and experience of the clinicians. Both endodontic instruments tested in this study were manufactured using different modifications of original NiTi alloy. Genius instruments are made from more austenitic NiTi alloy, while WO instruments are manufactured using M-wire NiTi alloy, which theoretically is more flexible and more resistant to cyclic fatigue [7,9]. However, the results of this study demonstrated that Genius instruments were more resistant to fractures, in comparison to WO files. However, there are no studies comparing the cyclic fatigue resistance of Genius and reciprocating instruments. Nevertheless, the 
results of this study are in agreement with the previous findings in regard to the average number of cycles/the time in seconds to failure/fracture (NCF) of the WO reciprocating instruments [30,31]. However, it should be mentioned that the main factors affecting the different cyclic resistances of the GN and WO instruments would be the differences in their cross-sections and the tapers of the instruments. Genius files have an S-shaped design, while the WO's files are concave triangles [31]. It has been reported that the instruments with the larger cross-sectional areas subsequently have a bigger instrument core and higher flexural stiffness [28,31]. Additionally, the taper of the WO instruments is bigger in comparison to that of GN files [7,9]. It can be summarized that WOs have higher torsional and flexural stiffness and lower cyclic fatigue resistance.

The SEM investigation of the new and unused GN and WO files revealed some differences between the two instruments. However, these differences can be related to slightly modified machining methods, applied during manufacturing of the files [7,9]. The fractographic analysis of the instruments after cyclic fatigue test did not reveal any significant difference between the two files tested. A typical topographic view of cyclic fatigue fractures was detected on cross-sectional fractured surfaces, such as crack origin zones, microscopic dimples on the fracture surface and fatigue and overload fast fracture zones. These findings and are in agreement with previous results [28-31]. However, the clinical importance of these differences is very questionable.

\section{Conclusions}

Within the limitations of this in vitro study, it can be concluded that hybrid GN instruments were able to remove less volume of dentin, prepare larger surfaces of the root canal walls with less root canal transportation and were more resistant to cyclic fatigue in comparison to reciprocating WO files. However, both systems investigated prepared the root canals with no significant shaping errors and made considerable changes in 3D parameters with no significant differences to the topographic appearances of the instrument surfaces after fractures.

Author Contributions: Conceptualization, S.D. and V.P.; data curation, V.B.; formal analysis, V.P.; investigation, S.D. and V.P.; methodology, S.D. and V.B.; project administration, R.B.; resources, E.N.; software, R.M.; supervision, S.D. and E.N.; visualization, R.M.; writing-original draft, S.D. and V.B.; writing-review and editing, V.P. and R.B. All authors have read and agreed to the published version of the manuscript.

Funding: This research received no external funding.

Acknowledgments: The authors would like to thank Dentsply Sirona and Ultradent Products Inc. for their gracious support and donation of the instruments.

Conflicts of Interest: The authors declare no conflict of interest. The sponsors had no role in the design of the study; in the collection, analyses, or interpretation of data; in the writing of the manuscript, and in the decision to publish the results.

\section{References}

1. Peters, O.A. Current challenges and concepts in the preparation of root canal systems: A review. J. Endod. 2004, 30, 559-567. [CrossRef] [PubMed]

2. Loizides, A.L.; Kakavetsos, V.D.; Tzanetakis, G.N.; Kontakiotis, E.G.; Eliades, G. A comparative study of the effects of two nickel-titanium preparation techniques on root canal geometry assessed by microcomputed tomography. J. Endod. 2007, 33, 1455-1459. [CrossRef] [PubMed]

3. Abou-Rass, M.; Frank, A.L.; Glick, D.H. The anticurvature filing method to prepare the curved root canal. J. Am. Dent. Assoc. 1980, 101, 792-794. [CrossRef] [PubMed]

4. Gutmann, J.L.; Gao, Y. Alteration in the inherent metallic and surface properties of nickel-titanium root canal instruments to enhance performance, durability and safety: A focused review. Int. Endod. J. 2012, 45, 113-128. [CrossRef] [PubMed]

5. Siqueira, J.F., Jr.; Alves, F.R.; Versiani, M.A.; Rocas, I.N.; Almeida, B.M.; Neves, M.A.; Sousa-Neto, M.D. Correlative bacteriologic and micro-computed tomographic analysis of mandibular molar mesial canals prepared by self-adjusting file, reciproc, and twisted file systems. J. Endod. 2013, 39, 1044-1050. [CrossRef] 
6. Zhao, D.; Shen, Y.; Peng, B.; Haapasalo, M. Micro-computed tomography evaluation of the preparation of mesiobuccal root canals in maxillary first molars with Hyflex CM, Twisted Files, and K3 instruments. J. Endod. 2013, 39, 385-388. [CrossRef]

7. Drukteinis, S.; Peciuliene, V.; Dummer, P.H.M.; Hupp, J. Shaping ability of BioRace, ProTaper NEXT and Genius nickel-titanium instruments in curved canals of mandibular molars: A MicroCT study. Int. Endod. J. 2019, 52, 86-93. [CrossRef]

8. Genius Reciprocating and Rotary Files; Genius Brochure; Ultradent products Inc.: South Jordan, UT, USA, 2016.

9. Berutti, E.; Chiandussi, G.; Paolino, D.S.; Scotti, N.; Cantatore, G.; Castellucci, A.; Pasqualini, D. Canal shaping with WaveOne Primary reciprocating files and ProTaper system: A comparative study. J. Endod. 2012, 38, 505-509. [CrossRef]

10. Stern, S.; Patel, S.; Foschi, F.; Sherriff, M.; Mannocci, F. Changes in centring and shaping ability using three nickel-titanium instrumentation techniques analysed by micro-computed tomography ( $\mu \mathrm{CT})$. Int. Endod. J. 2012, 45, 514-523. [CrossRef]

11. Marzouk, A.M.; Ghoneim, A.G. Computed tomographic evaluation of canal shape instrumented by different kinematics rotary nickel-titanium systems. J. Endod. 2013, 39, 906-909. [CrossRef]

12. Versiani, M.A.; Leoni, G.B.; Steier, L.; De-Deus, G.; Tassani, S.; Pecora, J.D.; de Sousa-Neto, M.D. Micro-computed tomography study of oval-shaped canals prepared with the self-adjusting file, Reciproc, WaveOne, and ProTaper universal systems. J. Endod. 2013, 39, 1060-1066. [CrossRef]

13. Peters, O.A.; Laib, A.; Ruegsegger, P.; Barbakow, F. Three-dimensional analysis of root canal geometry by high-resolution computed tomography. J. Dent. Res. 2000, 79, 1405-1409. [CrossRef]

14. Larsen, C.M.; Watanabe, I.; Glickman, G.N.; He, J. Cyclic fatigue analysis of a new generation of nickel titanium rotary instruments. J. Endod. 2009, 35, 401-403. [CrossRef]

15. Marceliano-Alves, M.F.; Sousa-Neto, M.D.; Fidel, S.R.; Steier, L.; Robinson, J.P.; Pecora, J.D.; Versiani, M.A. Shaping ability of single-file reciprocating and heat-treated multifile rotary systems: A micro-CT study. Int. Endod. J. 2015, 48, 1129-1136. [CrossRef]

16. De-Deus, G.; Belladonna, F.G.; Silva, E.J.; Marins, J.R.; Souza, E.M.; Perez, R.; Lopes, R.T.; Versiani, M.A.; Paciornik, S.; Neves Ade, E. Micro-CT Evaluation of Non-instrumented Canal Areas with Different Enlargements Performed by NiTi Systems. Braz. Dent. J. 2015, 26, 624-629. [CrossRef]

17. Schneider, S.W. A comparison of canal preparations in straight and curved root canals. Oral Surg Oral Med. Oral Pathol. 1971, 32, 271-275. [CrossRef]

18. Gambill, J.M.; Alder, M.; del Rio, C.E. Comparison of nickel-titanium and stainless steel hand-file instrumentation using computed tomography. J. Endod. 1996, 22, 369-375. [CrossRef]

19. Gergi, R.; Arbab-Chirani, R.; Osta, N.; Naaman, A. Micro-computed tomographic evaluation of canal transportation instrumented by different kinematics rotary nickel-titanium instruments. J. Endod. 2014, 40, 1223-1227. [CrossRef]

20. Azim, A.A.; Griggs, J.A.; Huang, G.T. The Tennessee study: Factors affecting treatment outcome and healing time following nonsurgical root canal treatment. Int. Endod. J. 2016, 49, 6-16. [CrossRef]

21. Gergi, R.; Osta, N.; Bourbouze, G.; Zgheib, C.; Arbab-Chirani, R.; Naaman, A. Effects of three nickel titanium instrument systems on root canal geometry assessed by micro-computed tomography. Int. Endod. J. 2015, 48, 162-170. [CrossRef]

22. Berutti, E.; Fedon, G. Thickness of cementum/dentin in mesial roots of mandibular first molars. J. Endod. 1992, 18, 545-548. [CrossRef]

23. Setzer, F.C.; Kwon, T.K.; Karabucak, B. Comparison of apical transportation between two rotary file systems and two hybrid rotary instrumentation sequences. J. Endod. 2010, 36, 1226-1229. [CrossRef]

24. Zhao, D.; Shen, Y.; Peng, B.; Haapasalo, M. Root canal preparation of mandibular molars with 3 nickel-titanium rotary instruments: A micro-computed tomographic study. J. Endod. 2014, 40, 1860-1864. [CrossRef]

25. Paque, F.; Ganahl, D.; Peters, O.A. Effects of root canal preparation on apical geometry assessed by micro-computed tomography. J. Endod. 2009, 35, 1056-1059. [CrossRef]

26. Wu, M.K.; R'Oris, A.; Barkis, D.; Wesselink, P.R. Prevalence and extent of long oval canals in the apical third. Oral Surg Oral Med. Oral Pathol Oral Radiol Endod. 2000, 89, 739-743. [CrossRef]

27. Burklein, S.; Schafer, E. Apically extruded debris with reciprocating single-file and full-sequence rotary instrumentation systems. J. Endod. 2012, 38, 850-852. [CrossRef] 
28. Pedullà, E.; Lo Savio, F.; Boninelli, S.; Plotino, G.; Grande, N.M.; La Rosa, G.; Rapisarda, E. Torsional and Cyclic Fatigue Resistance of a New Nickel-Titanium Instrument Manufactured by Electrical Discharge Machining. J. Endod. 2016, 42, 156-159. [CrossRef]

29. Hülsmann, M.; Donnermeyer, D.; Schäfer, E. A critical appraisal of studies on cyclic fatigue resistance of enginedriven endodontic instruments. Int. Endod. J. 2019, 52, 1427-1445. [CrossRef]

30. De-Deus, G.; Vieira, V.T.; da Silva, E.J.; Lopes, H.; Elias, C.N.; Moreira, E.J. Bending resistance and dynamic and static cyclic fatigue life of Reciproc and WaveOne large instruments. J. Endod. 2014, 40, 575-579. [CrossRef]

31. Plotino, G.; Testarelli, L.; Al-Sudani, D.; Pongione, G.; Grande, N.M.; Gambarini, G. Fatigue resistance of rotary instruments manufactured using different nickel-titanium alloys: A comparative study. Odontology 2014, 102, 31-35. [CrossRef]

(C) 2020 by the authors. Licensee MDPI, Basel, Switzerland. This article is an open access article distributed under the terms and conditions of the Creative Commons Attribution (CC BY) license (http://creativecommons.org/licenses/by/4.0/). 